\title{
Disentangling the Effects of Attitudes and Health on Consumer Purchase Intention Towards Herbal Products
}

\author{
* $1^{\text {st }}$ Dian Widyaningtyas \\ Faculty of Economics and Business \\ Universitas Sebelas Maret \\ Surakarta, Indonesia \\ Department of Management \\ Universitas Aisyiyah Yogyakarta \\ Yogyakarta, Indonesia \\ dianoer@gmail.com
}

\author{
$2^{\text {nd }}$ Wisnu Untoro \\ Faculty of Economics and Business \\ Universitas Sebelas Maret \\ Surakarta, Indonesia \\ wisnu.untoro@gmail.com \\ $5^{\text {th }}$ Lilik Wahyudi \\ Faculty of Economics and Business \\ Universitas Sebelas Maret \\ Surakarta, Indonesia \\ lilikwahyudi@hotmail.co.uk
}

\author{
$3^{\text {rd }}$ Ahmad Ikhwan Setiawan \\ Faculty of Economics and Business \\ Universitas Sebelas Maret \\ Surakarta, Indonesia \\ aikhwansse@gmail.com
}

\begin{abstract}
The use of herbal products has increased. Nowadays herbal are often used as complementary medicines in health therapy. This study aims to examine the roles of attitudes and health in predicting consumer intentions within the context of herbal products. It used the Theory of Planned Behavior to see how consumers perceive when buying herbal products. The relationships between attitudes and health towards consumers' intention were studied by applying Structural Equation Modelling. Based on the results of the study, attitudes have a significant impact on consumer intentions to use herbal products.
\end{abstract}

Keywords - consumers' purchase intention, health, attitudes, Theory of Planned Behavior, herbal products

\section{INTRODUCTION}

The demand for herbal products has increased in recent years due to the consciousness of natural products. Choosing food is one of the most important things that affect health. Nowadays, people are increasingly concerned about a healthy lifestyle. People argue that a healthy lifestyle is synonymous with nature. This shows the desire to choose natural products that are related to a healthier lifestyle [1]. Shifts in the consumption of natural products can be observed. Natural products are also called organic products or green products. In the types of plants that can be used for medicine, known as herbal products. Obviously, the need for healthy living has encouraged consumers to consume organic food [2], which further shows that organic products are healthier and safer [3]. The popularity of organic food is increasing. Herbal products are medicinal products that are organic, as it is a natural product and comes from plants.

Herbs are known as phytomedicine or plant medicine, which due to its properties has been widely used for generations. Written records of medicinal plants have existed for the Sumerians for 5000 years [4]. In it's development, medicinal plants were selected as health therapy. Growing trends in natural products that have led to several studies related to herbal products. Ref. [5] examined behavioral patterns and modalities decisions regarding the use of herbal medicines in a sample of Italian women. It has been reported that about half of those interviewed had used one or more herbal products in the past year. Ref. [6] reports that twenty percent of African Americans have used complementary alternative medicine (CAM) to treat certain diseases.

People are playing a more active role in their healthcare today. Changes in healthy lifestyles are becoming increasingly popular not only on the organic food, but also when reducing the use of chemicals in medicine. Side effects of chemical medicine encourage people to switch to natural products treatment. The demand for herbs is increasing [7], [8]. Complementary alternative medicine (CAM) is the main alternative treatment in the UK, Europe, North America and Australia [9].

There are some phenomena that occur in herbal products and encourage researchers to do more research. The results of previous studies have shown interesting things, namely:

1. Consumer interest in herbal products is growing rapidly in the last decade [10], [11], [4], [8].

2. The consumer behavior intention with herbal products is interesting to examine in more specific. Herbal products are made from natural ingredients and are not exposed to any side effects, consumers use herbal products because they believe that they are natural [5], safe and easily accessible [12], therefore people choose to use complementary alternative medicine [10]. In Indonesia, Jamu is a traditional Indonesian herbs that is very popular and used as a therapeutic treatment option [13].

\section{THEORY AND HYPOTHESIS}

\section{A. Theory}

Studies on consumer behavior towards herbal products are carried out to identify consumer trends and perspectives on questions of health and natural resources when using herbs and herbal products [7]. The tendency to correct behavior is influenced by attitudes towards treatment, subjective norms and accompanying treatment [14]. In 
particular, [15] states that attitudes to the use herbal products are the only significant predictor of the intention to use herbal medicines in the next six months. Herb consumption is influenced by demographic variables such as age, gender, level of education, income and ethnicity [16].

Research on consumer behavior intention in herbal products, explained by the Theory of Planned Behavior. The core of this theory consists of three things; namely beliefs about possible outcomes and assessments of these behaviors, beliefs about expected norms and motivations to meet these expectations (normative beliefs), and beliefs about the existence of factors that support the behavior (control beliefs).

Theory of Planned Behavior is an extension of Theory of Reason Action that is designed to predict behaviors that are not fully under individual control. Theory of Reason Action combines beliefs, attitudes, intentions and behavior. Theory of Reason Action was proposed by Azjen [17] and later developed on Theory of Planned Behavior [18].

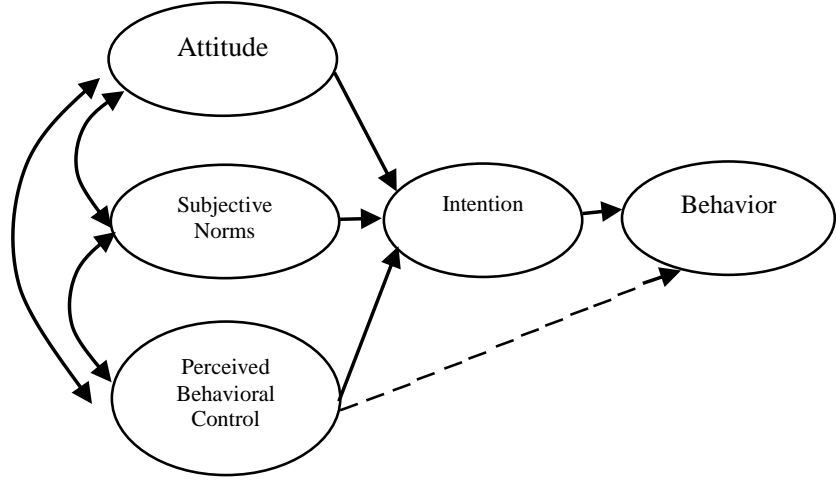

Fig. 1. Theory of Planned Behavior, adapted [18].

Theory of Planned Behavior provides a framework for learning attitudes to behavior. Based on theory, intent to behave is an important determinant of a person's behavior [17]. Theory of Planned Behavior predicts and understands the influence of motivation on behavior that is not under individual control. An individual's intention to display behavior is a combination of attitudes to indicate subjective behavior and norms.

Protection Motivation Theory is a theory developed by Rogers [19]. According to the Protection Motivation Theory, someone wants to do something because they have the motivation to be protected. Protection Motivation Theory is used in this study to determine a person's action to protect their health related to disease. The motivation to protect yourself depends on four factors: Perceived severity (severity), perceived vulnerability (vulnerability), received response, effectiveness (degree of effectiveness of responses); perceived self-efficacy (level of trust), trust of the individual in his ability to carry out the recommended behavior prevention [19].

\section{B. Research Hypothesis}

Attitude refers to the value of an object's rating. Individual beliefs will affect the attitude that will impact to behavior. Ref. [20] argue that attitudes can influence intention behavior. Individual beliefs influence the attitudes that influence behavior. Attitude had significant relationship with intention toward behaviors [21]. There is a significant relationship between attitude and intention and behavior [22]. Attitudes play an important role in assessing consumer intention and actual purchases [18], [23]. Proposals to explain the relationship between attitude and intention are based on the tendency of the phenomenon of positive relationship patterns. The higher the attitude that supports behavior, the higher the intention that someone should behave.

H1: Attitude will positively affect consumers' intentions of herbal products.

Regarding the theory of the Health Belief Model, a person takes action when he thinks that his health has serious consequences [24]. Consumers are motivated to improve their health and quality of life to stay healthy [25], [26]. While the results of the study by [27] state that attention to health (health awareness) does not only have a direct effect on the attitude of consumers, but also about the intentions of consumers towards products. The suggestion to explain the relationship between health and intention is based on the tendency of a positive relationship pattern phenomenon.

$\mathrm{H} 2$ : Perceived health of herbal products will positively affect the consumers' intentions.

\section{METHOD}

The data was collected from a purposive sample. The sample consisted of 100 consumers of herbal products in Indonesia. The respondent's characteristics describe the respondent's demographic background, including gender, age, education level and income.

Data were collected on a five-point Likert scale, ranging from "I completely disagree" to "I completely agree" Attitude measurements were adjusted by [15] and [18]. Hypotheses are tested with Structural Equation Modeling (SEM) techniques. SEM can be used to test a number of dependency relationships at the same time [28].

\section{RESULT AND DISCUSSION}

We examine an outer model evaluation (measurement model) and an inner model evaluation (structural model). The outer model is tested in order to assess the validity and reliability of the model [29].

\section{A. Outer Model Evaluation}

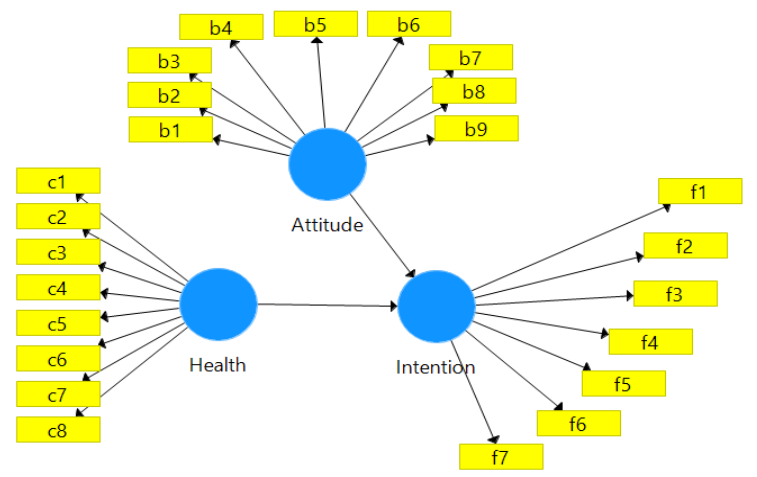

Fig. 2. Outer Model 
Convergent validity tests using the value of the average variance extracted (AVE). A variable can be accepted if the AVE value is above 0.5 [28].

TABLE I. CONVERGENT VALIDITY

\begin{tabular}{|l|c|}
\hline \multicolumn{2}{|c|}{ Convergent Validity } \\
\hline \multicolumn{1}{|c|}{ Variable } & Average Variance Extracted \\
\hline Attitude & 0,501 \\
\hline Health & 0,508 \\
\hline
\end{tabular}

Then the discriminant validity can be seen from the calculation of cross loading and latent variable correlations. The value of the calculation of cross loading shows that the correlation of indicators when measuring the construct has a higher value than the value of the correlation of indicators with other constructs. This shows the existence of good discriminant validity.

The construct reliability test is measured using Cronbach's alpha $(>0.6)$ and the composite reliability $(>0,7)$ of the indicators that measure the construct [30].

TABLE II. RELIABILITY

\begin{tabular}{|c|c|c|}
\hline \multicolumn{3}{|c|}{ Reliability } \\
\hline Variabel & Cronbach's alpha & $\begin{array}{l}\text { Composite } \\
\text { reliability }\end{array}$ \\
\hline Attitude & 0.886 & 0.888 \\
\hline Health & 0,857 & 0,902 \\
\hline
\end{tabular}

As Table II show, both attitudes and health are reliable, with composite reliability of attitude 0.888 and 0,902 of health.

Based on tests on the structural model, the model perform adequately with an R-square value of 0.415 , which means that the effect of construct variables on the intention variable results in an R-square value of 0.415 .

\section{B. Inner Model Evaluation}

The inner model is then tested to assess the strength of the estimates between latent or construct variables. Path coefficient weighting is used to show how strong the influence of independent variables is on the dependent variable.

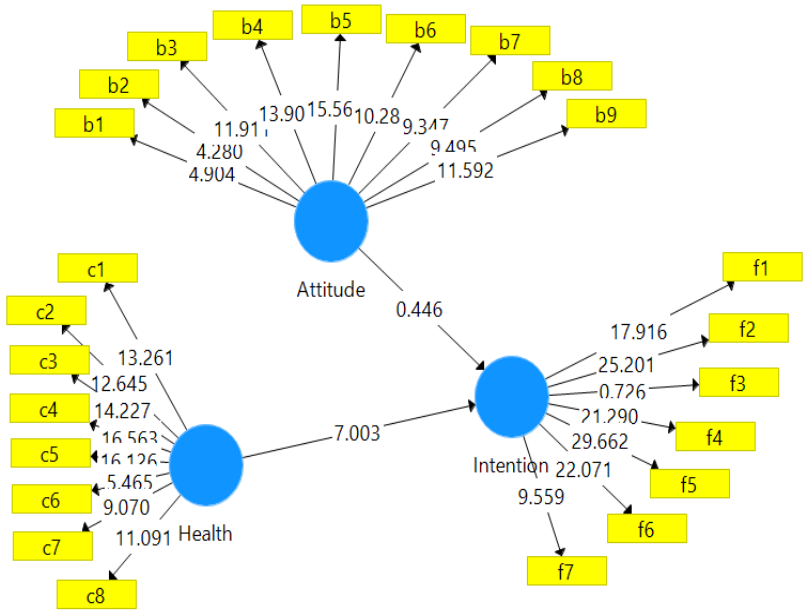

Fig. 3. Inner Model.

The results of the path coefficients showed that the direct impact of attitude to consumer intention indicate that the value of the path coefficient of 0.613 with a t-statistic of 6.633 is greater than $\mathrm{t}$ table 1.96 ( $\mathrm{t}$ statistic $>\mathrm{t}$ table), therefore attitude has a significant positive impact to the intention. As table III, the results of the path coefficients showed that the direct impact of health on consumer intention indicate the value of the path coefficient of 0,045 and t-statistic of 0,468 .

TABLE III. PATH COEFFICIENT

\begin{tabular}{|c|c|c|}
\hline \multicolumn{3}{|c|}{ Path Coefficient } \\
\hline \multicolumn{1}{|c|}{ Variable } & Path & T-Statistic \\
\hline Attitude $\rightarrow$ Intention & 0.613 & 6.633 \\
\hline Health $\rightarrow$ Intention & 0,045 & 0,468 \\
\hline
\end{tabular}

\section{Hypothesis test}

The results of the hypothesis tests are created based on the t-statistic and the P-value. The research hypothesis can be accepted if the $\mathrm{P}$-value is $<0.05$.

TABLE IV. RESULT

\begin{tabular}{|l|c|c|}
\hline \multirow{2}{*}{ Variable } & \multicolumn{2}{|c|}{ Hypothesis } \\
\cline { 2 - 3 } & P Values & Result \\
\hline Attitude $\rightarrow$ Intention & 0,000 & Supported \\
\hline Health $\rightarrow$ Intention & 0,640 & Not Supported \\
\hline
\end{tabular}

Hypothesis tests are to see the effects of health and attitude on consumer intention to use herbal products. The results of the hypothesis show that hypotheses 1 is supported, attitude has a positive impact on consumer intentions. Support is not found for hypotheses 2, relating to the direct relationships between health and consumer intentions.

\section{Discussion}

Based on the results of the data analysis with SmartPLS 3.0, as shown in Table IV, it can be seen that p-value is 0.00 
$<0.05$ and the value of t-Statistics to represent the significance of the effect is 6.633 greater than t-table $1.96(\mathrm{t}$ Statistics $>\mathrm{t}$ table). Hypothesis 1 is supported. This means that attitude has a significant impact on consumer intentions when using herbal products.

The relationship between attitude and intention shows that attitude has significant affect on consumers' intentions. A p-value of 0.000 means that the higher the attitude when using herbal products, the higher the consumer's intention to use herbal products. The results of this study are consistent [14]. Ref. [14] reports on the factors that influence the preferences for herbal supplements among Malaysian consumers. The results of the study show that attitudes is the main determinants of the tendency of consumers to make decisions to consume herbal products. The result study of the influence of attitude on intention also in line with [31] [22].

The results of examining the effect of health on consumer intention shows that p-value is $0.640>0.05$ and t-statistic health for intention is less than t-table $(0.468<1.96)$. Based on these results, it can be concluded that the second hypothesis 2 is not supported. This means that health does not affect consumer intentions when using herbal products.

The relationship between health and intention has no significant affect with a significance p-value of 0.640 . This indicates that health has a negative influence on the intention of consumers to use herbal products. The results of this study are in line with the studies of [32] and [33]. A survey of 712 respondents in Bangladesh interviewed by [33] to investigate the effects of consumer health consciousness, perceived knowledge, and beliefs that affect attitudes and consumer purchases intention. The data were analyzed using confirmation factors and structural equation modeling. The result of the study shows that consumer health consciousness has a positive effect on the perception of knowledge, trust and attitudes, but health consciousness does not influence purchasing intentions.

\section{CONCLUSION}

This study uses Theory of Planned Behavior to observe consumer perception of herbal products. Two behavioral variables were examined in relation to consumer intentions, namely attitudes and health. The results of the data analysis lead to the conclusion that attitudes influence the consumer's intention to use herbal products. This study also shows that the theory of planned behavior can be applied to healthrelated behavioral research

\section{ACKNOWLEDGMENT}

This work is partially supported by Indonesia Endowment Fund for Education (Lembaga Pengelola Dana Pendidikan Republik Indonesia)

\section{REFERENCES}

D. T. Ogden, "To buy or not to buy? A social dilemma perspective on green buying," vol. 6, pp. 376-391, 2009, doi: 10.1108/07363760910988201.

[2] S. P. Kalafatis, M. Pollard, R. East, M. H. Tsogas, and M.Pollard, Green marketing and Ajzen' $s$ theory of planned behaviour: a cross-market examination. 2005

[3] G. Vindigni, S. Economico-agrarie, and M. A. Janssen, "Organic food consumption A multi-theoretical framework of consumer decision making," vol. 104, no. 8, pp. 624-642, 2001, doi: 10.1108/00070700210425949.

[4] A. Sharma, C. Shanker, L. K. Tyagi, M. Singh, and C. V. Rao, "Herbal Medicine for Market Potential in India: An Overview," Acad. J. Plant Sci., vol. 1, no. 2, pp. 26-36, 2008, doi: $10.1177 / 1534582306289130$.

[5] Z. S., C. L., and B. G., "Herbal products: Behaviors and beliefs among Italian women," Pharmacoepidemiol. Drug Saf., vol. 15, no. 5, pp. 354-359, 2006, doi: 10.1002/pds.1190.

[6] J. C. Barner, T. M. Bohman, C. M. Brown, and K. M. Richards, "Use of complementary and alternative medicine for treatment among African-Americans: A multivariate analysis," Res. Soc. Adm. Pharm., vol. 6, no. 3, pp. 196-208, 2010, doi: 10.1016/j.sapharm.2009.08.001.

[7] K. Kinabalu, S. An, and I. Study, "Factors Related to the Use of Herbal Products and Derivatives from Consumers 'Perspective in Kota Kinabalu, Sabah : An Initial Study," no. January, 2010.

[8] S. Ismail and S. S. M. Mokhtar, "The antecedents of herbal product actual purchase in Malaysia," Manag. Sci. Lett., vol. 5, pp. 771-780, 2015, doi: 10.5267/j.msl.2015.5.011.

[9] M. Ekor, "The growing use of herbal medicines : issues relating to adverse reactions and challenges in monitoring safety," vol. 4, no. January, pp. 1-10, 2014, doi: 10.3389/fphar.2013.00177.

[10] F. L. Bishop, L. Yardley, and G. T. Lewith, "Why do people use different forms of complementary medicine? Multivariate associations between treatment and illness beliefs and complementary medicine use," Psychol. Heal., vol. 21, no. 5, pp. 683-698, 2006, doi: 10.1080/14768320500444216.

[11] F. M. Alkhateeb, W. R. Doucette, and J. M. Ganther-Urmie, "Influences on consumer spending for herbal products," Res. Soc. Adm. Pharm., vol. 2, no. 2, pp. 254-265, 2006, doi: 10.1016/j.sapharm.2006.03.001

[12] M. Alwhaibi, K. M. Kelly, M. Alwhaibi, R. Goyat, and K. M. Kelly, "The Use of Herbal Remedies among Mothers of Young Children Living in the Central Appalachian Region The Use of Herbal Remedies among Mothers of Young Children Living in the Central Appalachian Region," 2017.

[13] Elfahmi, H. J. Woerdenbag, and O. Kayser, "Jamu: Indonesian traditional herbal medicine towards rational phytopharmacological use," J. Herb. Med., vol. 4, no. 2, pp. 5173, 2014, doi: 10.1016/j.hermed.2014.01.002.

[14] A. S. Mohamed, "Factors Influencing Intention to Consume Herbal Supplement," March, 2004, unpublished.

[15] G. V. Gupchup, U. L. Abhyankar, M. M. Worley, D. W. Raisch, A. A. Marfatia, and R. Namdar, "Relationships between Hispanic ethnicity and attitudes and beliefs toward herbal medicine use among older adults," Res. Soc. Adm. Pharm., vol. 2, no. 2, pp. 266-279, 2006, doi: 10.1016/j.sapharm.2006.02.002

[16] M. N. S. and M. Z. Z. G. Rezai, Z. Mohamed, "Effect of Consumer Demographic Factors on Purchasing Herbal Products Online in Malaysia," Int. J. Econ. Manag. Eng., vol. 7, no. 8, pp. 2380-2386, 2013, [Online]. Available: www.lelong.com.my.

[17] I. Ajzen and M. Fishbein, "Factors Influencing Intentions and the Intention-Behavior Relation," Hum. Relations, vol. 27, no. 1, pp. $1-15,1975$

[18] I. Ajzen, "The Theory of Planned Behavior," Organ. Behav. Hum. Decis. Process., vol. 50, pp. 179-211, 1991.

[19] R. W. Rogers and S. Prentice-Dunn, "Protection motivation theory and preventive health: Beyond the health belief model," Health Educ. Res., vol. 1, no. 3, pp. 153-161, 1986.

[20] I. Fishbein, M., \& Ajzen, Belief, Attitude, Intention, and Behavior: An Introduction to Theory and Research. Reading, MA: Addison-Wesley, 1975.

[21] J. Li, D. Mizerski, A. Lee, and F. Liu, "The relationship between attitude and behavior: an empirical study in China," 2009, doi: $10.1108 / 13555850910950059$

[22] A. Tarkiainen and S. Sundqvist, "Subjective norms, attitudes and intentions of Finnish consumers in buying organic food," $\mathrm{Br}$. Food J., vol. 107, no. 11, pp. 808-822, 2005, doi: 10.1108/00070700510629760

[23] E. L. O. Connor and K. M. White, "Complementary Therapies in Clinical Practice Intentions and willingness to use complementary and alternative medicines: What potential patients believe about CAMs," Complement. Ther. Clin. Pract., vol. 15, no. 3, pp. 136-140, 2009, doi: 10.1016/j.ctcp.2009.03.003. 
[24] I. M. Rosenstock, "Historical origins of the health belief model. Health Education Monographs,2, 328-335," Health Educ. Monogr., vol. 2, no. 4, pp. 328-335, 1974.

[25] J. T. Newsom, B. H. Mcfarland, M. S. Kaplan, N. Huguet, and B. Zani, "The health consciousness myth : implications of the near independence of major health behaviors in the North American population," vol. $60, \quad$ pp. 433-437, 2005, doi: 10.1016/j.socscimed.2004.05.015.

[26] R. E. Plank and S. J. Gould, "Health Marketing Quarterly Health Consciousness , Scientific Orientation and Wellness," no. March 2015, pp. 37-41, 2008, doi: 10.1300/J026v07n03.

[27] N. Michaelidou and L. M. Hassan, "The role of health consciousness, food safety concern and ethical identity on attitudes and intentions towards organic food," Int. J. Consum. Stud., vol. 32, no. 2, pp. 163-170, 2008, doi: 10.1111/j.14706431.2007.00619.x.

[28] M. Sarstedt, C. M. Ringle, and J. F. Hair, Partial Least Squares Structural Equation Modeling.

[29] I. Ghozali and H. Latan, Partial Least Squares Concepts, Techniques and Applications, Smart PLS 3.0. Diponegoro
University Publisher Agency, Semarang Indonesia, 2012.

[30] W. W. Chin and J. Dibbern, Handbook of Partial Least Squares. An introduction to a permutation based procedure for multi-group PLS Analysis : Result of test of differences on simulated data and cross cultural analysis of the sourcing of information system service between Germany and USA. Springer Handbooks of Computational Statistics, Springer Heidelberg, 2010.

[31] K. Byrka, General attitude - specific behavior: bidirectional prediction, no. January 2009. 2009.

[32] T. A. Phan and P. H. Mai, "Determinants Impacting Consumers' Purchase Intention: The Case of Fast Food in Vietnam," Int. J. Mark. Stud., vol. 8, no. 5, p. 56, 2016, doi: 10.5539/ijms.v8n5p56.

[33] M. Z. Houqe, M. N. Alam, and K. A. Nahid, "Health Consiousness and Its Effect on Perceived Knowledge, and Belief in the Purchase Intent of Liquid Milk: Consumer Insights from an Emerging Market," Foods MDPI, 2018, doi: 10.3390/foods7090150 